\title{
Dual localized scanning plasmon resonance and electrochemical investigations of organophosphorus insecticides presence $\uparrow$
}

Received 26th September 2013 Accepted 8th November 2013

DOI: $10.1039 / c 3 r a 45413 d$

www.rsc.org/advances

\author{
Farkhondeh Fathi, Chandrika Vijayaratnam and Heinz-Bernhard Kraatz
}

The application of electrochemically prepared Ag nanostructures (NSs) for fast monitoring of sulfur containing organophosphonates, ethion, malathion and fenthion, in real two natural matrices, tap-water and apple juice, has been investigated using localized surface plasmon resonance and electrochemical techniques. The results show a limit of detection of $10 \mu \mathrm{M}$ for ethion and $100 \mu \mathrm{M}$ for malathion and fenthion.

\section{Introduction}

Organophosphorus (OP) compounds containing a thiophosphoryl $(\mathrm{P}=\mathrm{S})$ functional group are generally used as insecticides for agricultural applications. ${ }^{1,2}$ They exhibit a high level of toxicity due to disabling of the central nervous system by irreversibly binding to acetyl cholinesterase. ${ }^{2}$ Continual application of OP compounds in farm lands worldwide has led to their presence as the residual not only in agricultural products, but also has resulted to their seepage into underground water sources which is causing significant problems. ${ }^{3,4}$

Currently gas and liquid chromatography ${ }^{5,6}$ and mass spectroscopy ${ }^{7}$ are used for OPs residual detection, also there has been some reports on development of biosensors based on the cholinesterase activity inhibition, ${ }^{8-11}$ electrochemical, fluorescence, colorimetric and quartz crystal microbalance; $;^{2,3,12,13}$ however there is still a continued high demand of developing new materials which interacts strongly with OPs and can be used for quick monitoring of them in robust or complicated conditions using more portable, sensitive and low cost techniques from practical perspective. ${ }^{14,15}$

In this context, the use of metal nanoparticles (NPs), in particular silver NPs provides a new analytical angle and has potential for significant advances. Different methodologies have been applied for the synthesis of Ag NSs and interestingly they have found applications in electrochemical and localized surface plasmon resonance (LSPR) techniques for sensing of a broad range of analytes, are readily available at a low cost and pose no issues related to fabrication. ${ }^{16-23}$

Department of Physical and Environmental Sciences, University of Toronto Scarborough, 1265 Military Trail, Toronto, M1C 1A4 and Department of Chemistry, University of Toronto, 80 St. George Street, Toronto, M5S 3H6, Canada. E-mail: bernie.kraatz@utoronto.ca; Tel: +1-416-287-7278

$\dagger$ Electronic supplementary information (ESI) available. See DOI: $10.1039 / \mathrm{c} 3 \mathrm{ra} 45413 \mathrm{~d}$

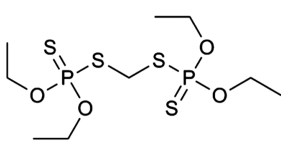

1

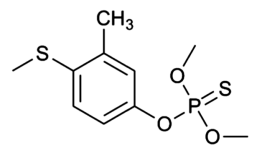

2

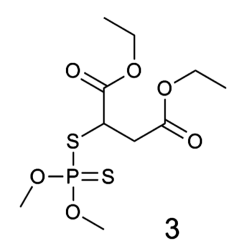

3
Scheme 1 Chemical structure of ethion 1, fenthion 2 and malathion 3.

Previously we reported a simple electrochemical method for fabrication of nanostructured $\mathrm{Ag}$ substrates. ${ }^{24}$ In addition these Ag nanostructures (NSs) were successfully applied for detection of two OPs, paraoxon and malathion at ppm levels using surface enhanced Raman spectroscopy. ${ }^{25}$ This result has prompted us to evaluate the use of LSPR for OP detection on Ag NSs and here we describe the results of our study into the use of LSPR for monitoring the presence of the three organophosphate pesticides ethion, fenthion and malathion (Scheme 1).

\section{Experimental section}

\section{Reagents}

$\mathrm{KOH}, \mathrm{KNO}_{3}, \mathrm{Na}_{2} \mathrm{SO}_{4}, \mathrm{H}_{2} \mathrm{SO}_{4}$, and ethanol were purchased from Caledon and used as received. $\mathrm{CdSO}_{4}, \mathrm{Ru}\left[\left(\mathrm{NH}_{3}\right)_{6}\right] \mathrm{Cl}_{3}$, ethion, fenthion malathion were purchased from Sigma-Aldrich and used as received. Apple juice (Simply Food) was used as received. Deionized water $(18.2 \mathrm{M} \Omega \cdot \mathrm{cm}$ resistivity) from a Millipore MilliQ system was used throughout this work. The Ag foil (thickness $=0.28 \mathrm{~mm}, 99.9 \%$ metal basis) and platinum wire ( $0.25 \mathrm{~mm}$ diameter, $99.9 \%$ metal basis) were purchased from Alfa Aesar.

\section{Electrochemistry}

All electrochemical experiments, including under potential deposition (UPD), square wave voltammetry (SWV) and 
electrochemical impedance spectroscopy (EIS) were performed using a CHI660B electrochemical workstation (CH Instruments Inc.), using a $10 \mathrm{~mL}$ homemade Teflon cell in a three-electrode setup for holding the silver foil. A coiled Pt wire was used as an auxiliary electrode and $\mathrm{Ag} / \mathrm{AgCl}(3 \mathrm{M} \mathrm{KCl}, \mathrm{CH}$ Instruments, Inc.) served as a reference electrode. The reference electrode always was separated from the cell by a miniature homemade salt bridge (agar and $\mathrm{KNO}_{3}$ ) to minimize the contamination of the electrochemical cell with $\mathrm{Cl}^{-}$ions. All measurements were carried out at room temperature $\left(23 \pm 2{ }^{\circ} \mathrm{C}\right)$ in an enclosed and grounded Faraday cage. Electrochemical measurements were performed in $1.0 \mathrm{M} \mathrm{KNO}_{3}$ containing $1.0 \mathrm{mM} \mathrm{Ru}\left[\left(\mathrm{NH}_{3}\right)_{6}\right] \mathrm{Cl}_{3}$. The SWV measurements were carried out in the potential range of -0.4 to $0 \mathrm{~V}$ with a step potential of $0.004 \mathrm{~V}$, frequency at 10 $\mathrm{Hz}$, quiet time at $2 \mathrm{~s}$ and a pulse amplitude of $20 \mathrm{mV}$. All EIS measurements were performed in the frequency range of $1 \mathrm{~Hz}$ to $100 \mathrm{kHz}$ with an AC amplitude of $5 \mathrm{mV}$. The initial potential was adjusted to $-0.130 \mathrm{~V}$ for all measurements. The measured EIS by ZSimpWin 3.22 (Princeton Applied Research) and the data were presented in Nyquist plots. Underpotential deposition (UPD) of cadmium were carried out in an aqueous solution of $0.1 \mathrm{M} \mathrm{Na}_{2} \mathrm{SO}_{4}$ and $6 \mathrm{mM} \mathrm{CdSO}_{4}$. The $\mathrm{pH}$ was adjusted to $\mathrm{pH}=$ 5 by $\mathrm{H}_{2} \mathrm{SO}_{4}$ addition. UPD measurements were carried out in the range of -1.200 to $0.200 \mathrm{~V}(\mathrm{vs}$. $\mathrm{Ag} / \mathrm{AgCl})$ at the scan rate of $10 \mathrm{mV}$ $\mathrm{s}^{-1}$ and a quiet time of $30 \mathrm{~s}^{26-28}$

Importantly, all measurements were repeated for a minimum of three times with separate electrodes to obtain statistically significant results.

\section{Optical measurements}

The optics system set up is composed of a spectrophotometer (USB-4000-UV-vis), a tungsten halogen light source (LS-1-LL, wavelength range 200-1100 nm), a fiber probe bundle (fiber core diameter $400 \mu \mathrm{m}$, wavelength range 300-1100 nm) and WS1 diffuse reflectance standard, all purchased from Ocean Optics (Dunedin, USA). The diffuse reflectance standard was used as a Lambertian reference surface. The UV-vis probe was placed close to the working electrode surface so that incident light was reflected upon hitting the surface and then reflected back to the detector situated in the light probe. The intensity and wavelengths of spectral peaks were recorded as modifications were made to the surface. The probe height was held constant $(\sim 1$ $\mathrm{mm}$ above the sample surface) throughout this study. All experiments were performed at room temperature.

\section{Surface preparation}

A nanostructured $\mathrm{Ag}$ surface was prepared by a standard CV experiment using a three-electrode setup with the silver surface as the working electrode. Ag surface was washed for $30 \mathrm{~s}$ in the boiling ethanol before and after roughening process and then rinse with MilliQ water. The Ag was cycled for $5 \mathrm{CV}$ cycles in a potential range of -0.5 and $0.9 \mathrm{~V} v s$. $\mathrm{Ag} / \mathrm{AgCl}$ at a scan rate of $150 \mathrm{mV} \mathrm{s}^{-1}$ at $8.0 \mathrm{M} \mathrm{KOH}$ solution.

\section{Immobilization of insecticides}

Solution of the insecticides ethion, fenthion and malathion (Scheme 1) were prepared at various concentration in dried ethanol and then were immobilized onto the roughened $\mathrm{Ag}$ surface during their incubation for $72 \mathrm{~h}$ at $5{ }^{\circ} \mathrm{C}$. The surface was thoroughly washed using absolute ethanol and MilliQ water after incubation. The electrode was dried in the air and immediately transferred to the electrochemical cell for the measurement. Tests were repeated in apple juice and tap water with organophosphonates added to the test solution.

\section{Surface area measurement}

Since changes in the experimental conditions affect the size of the $\mathrm{Ag} \mathrm{NSs},{ }^{24}$ the active surface area needed to be determined. This was achieved by underpotential deposition (UPD) of cadmium. ${ }^{26}$ Our results show the highest surface area (5.90 \pm $0.10 \mathrm{~cm}^{2}$ ) was achieved after 5 cycles and these are used for all further studies (see supplementary information Fig. S1 and Table $\mathrm{S} 1 \dagger$ ).

\section{Results and discussion}

\section{Electrochemical studies of OP-modified Ag NSs}

The electrochemical properties of this system were investigated by SWV and EIS in the potential range of -0.4 to $0.0 \mathrm{~V}(v s . \mathrm{Ag} /$ $\mathrm{AgCl}$ ) in $1.0 \mathrm{M} \mathrm{KNO}_{3}$ containing $1.0 \mathrm{mM}$ concentration of the cationic redox probe $\mathrm{Ru}\left[\left(\mathrm{NH}_{3}\right)_{6}\right] \mathrm{Cl}_{3}$ before and after OP (Scheme 1) immobilization on the Ag NSs substrates.

EIS allows the characterization of the electrical properties of the interface..$^{29,30}$ This approach has been employed previously to examine various sensing and biosensing systems. ${ }^{31,32}$ The sensitivity of these substrates toward ethion using SWV and EIS is as low as $100 \mathrm{nM}$, while it is $10 \mu \mathrm{M}$ for fenthion and malathion in ethanolic solution (see Fig. S2-S4, ESI†). Upon incubation of the $\mathrm{Ag}$ NSs substrates in the solution containing OPs (ethanolic solution, tap water and apple juice) the current signal in either SWV is decreased due to presumably the formation of an OP thin film on the NS surface, which increases the resistance to charge transfer (see Fig. 1 and 2).

It appears that the signal intensity decreases as the number of $\mathrm{S}$ atoms in the backbone of the OP increases along the order of ethion $>$ malathion $\approx$ fenthion. Presumabaly this is due to stronger interactions between the Ag surface and the OP as the number of interacting sites in the molecule increase. ${ }^{32,33}$ Previous studies on the detection of OPs by differential pulse voltammetry reported detection limits of $10^{-12} \mathrm{M}, 10^{-8} \mathrm{M}$ and $10^{-9} \mathrm{M}$ for ethion, fenthion and malathion respectively using modified glassy carbon electrode with phenazine compounds under $\mathrm{N}_{2}$ gas. ${ }^{3}$ However, the responses were measured in a buffer under controlled conditions and not in complex matrices.

The SWV carried out on Ag NSs substrates before and after modification with $100 \mu \mathrm{M}$ and $1 \mathrm{mM}$ of OPs in apple juice and water to investigate the relationship between concentration of OPs and the current change (Fig. 1A-B). 

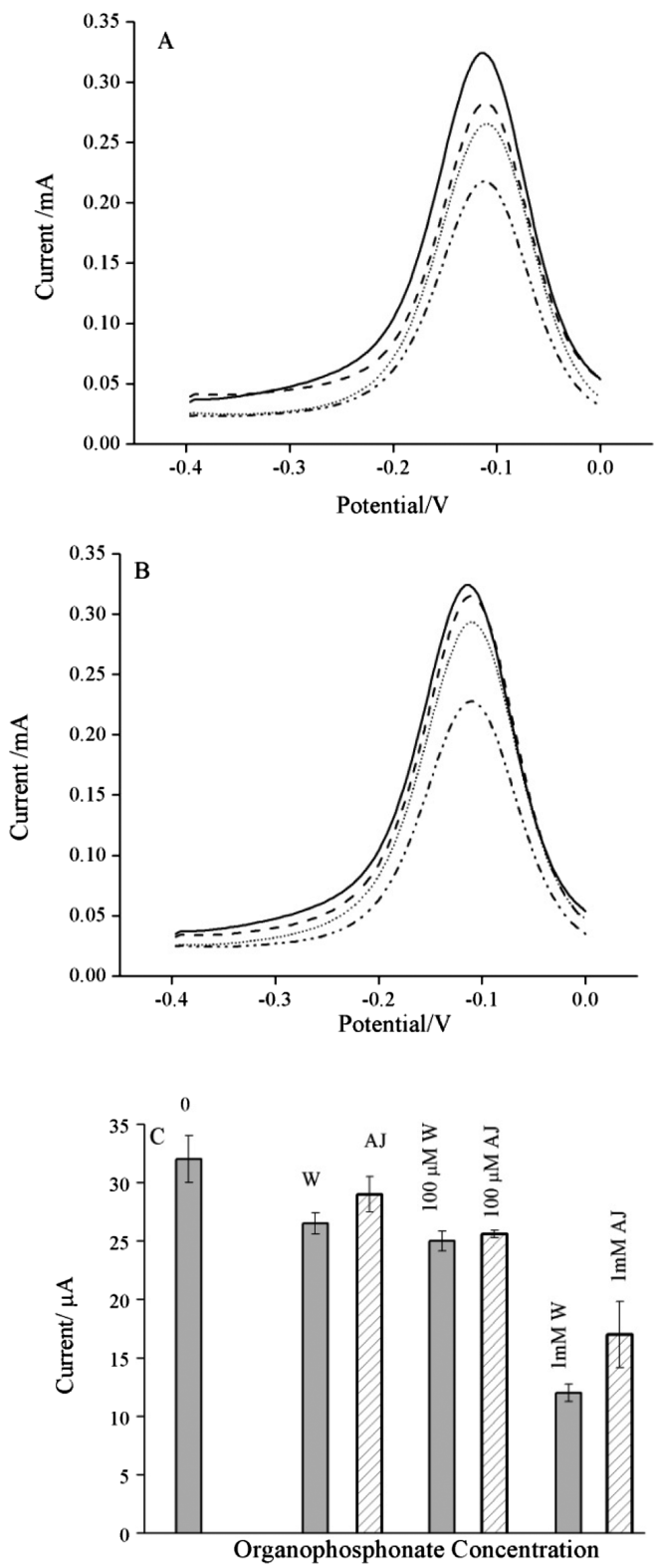

Fig. 1 SWVs of modified Ag NSs substrates with OPs in water (A) and apple juice (B). In both graphs lines are as following, bare Ag NSs (solid lines), modified with tap-water or apple juice (dash lines), modified with $100 \mu \mathrm{M}$ OPs in tap-water or apple juice (dot lines) and modified with $1 \mathrm{mM}$ OPs in tap-water or apple juice (dash dot dot lines). SWVs were performed in the potential range of -0.4 to $0 \mathrm{~V} v \mathrm{vs} . \mathrm{Ag} / \mathrm{AgCl}$ at a scan rate of $0.1 \mathrm{~V} \mathrm{~s}^{-1}$. with a step potential of $0.004 \mathrm{~V}$, frequency at 10 $\mathrm{Hz}$, quiet time at $2 \mathrm{~s}$ and a pulse amplitude of $0.02 \mathrm{~V}$ in a solution of $1 \mathrm{M}$ $\mathrm{KNO}_{3}$ containing $1 \mathrm{mM}\left[\mathrm{Ru}\left(\mathrm{NH}_{3}\right)_{6}\right] \mathrm{Cl}_{3}$ as redox probe. The current signal intensity decreases in both cases with OPs concentration enhancement. (C) Demonstrated the relation between current intensity and OPs concentration in water (W) and apple juice (AJ). The current intensity decrease with OPs concentration enhancement is slightly more for tap-water than apple-juice, which could be because of the less complex matrix.

The observed current reduction is due to an increase in resistance of the Ag NSs substrates caused by OP film formation on the interface layer. Increasing the OP concentration in both systems gives rise to a decrease of the current intensity.
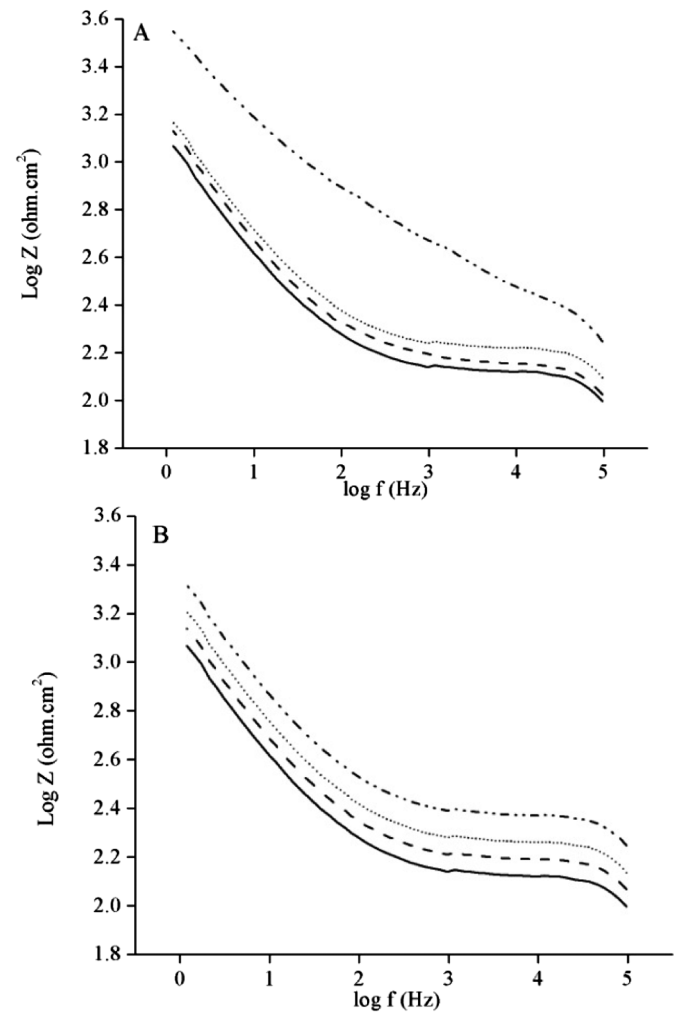

C
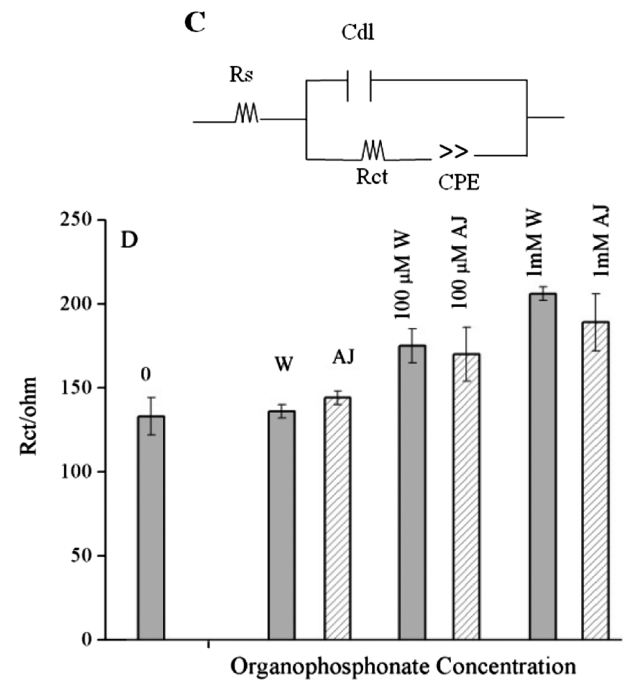

Fig. 2 Bode plots of modified Ag NSs with OPs in tap-water (A) and apple juice (B). In both graphs lines are as following, bare Ag NSs (solid lines), modified with tap-water or apple juice (dash lines), modified with $100 \mu \mathrm{M}$ OPs in tap-water or apple juice (dot lines) and modified with $1 \mathrm{mM}$ OPs in tap-water or apple juice (dash dot dot lines). EIS measurements were performed in a solution of $1 \mathrm{M} \mathrm{KNO}_{3}$ containing $1 \mathrm{mM}\left[\mathrm{Ru}\left(\mathrm{NH}_{3}\right)_{6}\right] \mathrm{Cl}_{3}$ as redox probe. They were acquired at the formal half potential of the $\left[\mathrm{Ru}\left(\mathrm{NH}_{3}\right)_{6}\right] \mathrm{Cl}_{3}(-0.17 \mathrm{~V}$ vs. $\mathrm{Ag} / \mathrm{AgCl})$ at $5 \mathrm{mV}$ amplitude and in the $0.1 \mathrm{~Hz}$ to $100 \mathrm{kHz}$ range. (C) Demonstrates a modified Randles's equivalent circuit: $R_{\mathrm{s}}$, the solution resistance; $C_{\mathrm{dl}}$, the double layer capacitance; $R_{\mathrm{ct}}$, the charge transfer resistance and CPE is the constant phase element. (D) Demonstrates the relation between $R_{\mathrm{ct}}$ and OPs concentration, clearly $R_{\mathrm{ct}}$ increases due to OPs concentration's enhancement.

To further explore the electrochemical characterization of the films, EIS studies were carried out. EIS studies provide 
information about the organic film in which the physical properties can be interpreted in terms of capacitive and resistive properties with the help of an equivalent circuit. $^{34}$ Fig. 2 shows the Bode plots for OP-modified Ag NSs substrates in tap-water and apple juice and Fig. 2C shows a modified Randles' circuit that was used to fit the experimental EIS data and rationalize the experimental results.

In the proposed circuit, $R_{\mathrm{s}}$ accounts for the solution resistance of the electrolyte solution and is a function of the supporting electrolyte concentration. The $R_{\mathrm{S}}$ is in series with a circuit which used to describe the $\mathrm{OP} /$ solution interface. The $C_{\mathrm{dl}}$ in the circuit demonstrating the double layer capacitance, $R_{\text {ct }}$ represents the OP film/solution interface related to the $\mathrm{Ru}(\mathrm{III} / \mathrm{II})$ redox process. The constant phase element, CPE, represents the frequency dispersion of the pseudocapacitance due to the surface inhomogeneity. ${ }^{31} \mathrm{CPE}$ impedance is given by $Z_{\mathrm{CPE}}=1 / Q(j \times \omega)^{n}$, where $Q$ is the frequency-independent constant correlating to the redox properties of the surface, $j=$ $-1^{1 / 2}, \omega$ represents the angular frequency, and the exponent $n$ arises from the slope of $\log Z v s . \log f(-1 \leq n \leq 1)$.

The CPE acts as a pure resistance for $n=0$; the CPE behaves as a pure capacitor for $n=1$, and CPE behaves as an inductor for $n=-1$. The CPE is attributed to a Warburg impedance for $n=0.5$, that is incorporated with the mass transport because of diffusion of ions at the electrode/solution interface. The calculated impedance spectrum are shown with solid line and are in good agreement with the experimental data points (see ESI, Fig. S5-S9†). The increase of OP concentration in any of the solutions tested gives rise to an increase of the charge transfer resistance $R_{\text {ct }}$ (Fig. 2D and $\mathrm{S} 3-\mathrm{S} 5 \dagger$ ).

These results are compatible with the SWVs results as well, suggesting detection of $\mathrm{P}=\mathrm{S}$ containing OPs to a concentration as low as $100 \mu \mathrm{M}$.

Previously work on the detection of OPs by EIS using interdigitated gold electrodes modified with benzodipyrido $\left[3,2-a: 2^{\prime} 3^{\prime}-c\right]$ phenazine demonstrated sensitivity as low as 1 $\mathrm{mM}$ for ethion, $1 \mu \mathrm{M}$ for malathion and $1 \mathrm{pM}$ for fenthion. ${ }^{2}$ The results of the EIS study reported here are comparable for ethion, but more work is required to optimize the system for fenthion and malathion by modification of the Ag NSs substrates.

\section{Localized surface plasmon resonance}

Next, the LSPR behaviour of OP-modified Ag NSs was examined. Earlier results showed that nanostructured-Ag substrates exhibit an outstanding surface plasmon properties which make them a suitable candidate for use as SERS substrate. ${ }^{25}$

The results for the addition of OPs to $\mathrm{Ag}$ NSs surface and their corresponding changes in absorbance intensity compared to control surface are shown in Fig. 3 (see also ESI, Fig. S10-S12 $\dagger$ ). Our LSPR results show that the $400 \mathrm{~nm}$ peak intensity decreases by increasing the OP concentration. The slight reduction of peak intensity in pure tap-water and juice may arise as a result of be due to absorbance of other compounds in the solution on the surface. All LSPR results are compatible with electrochemical results. To the best of our
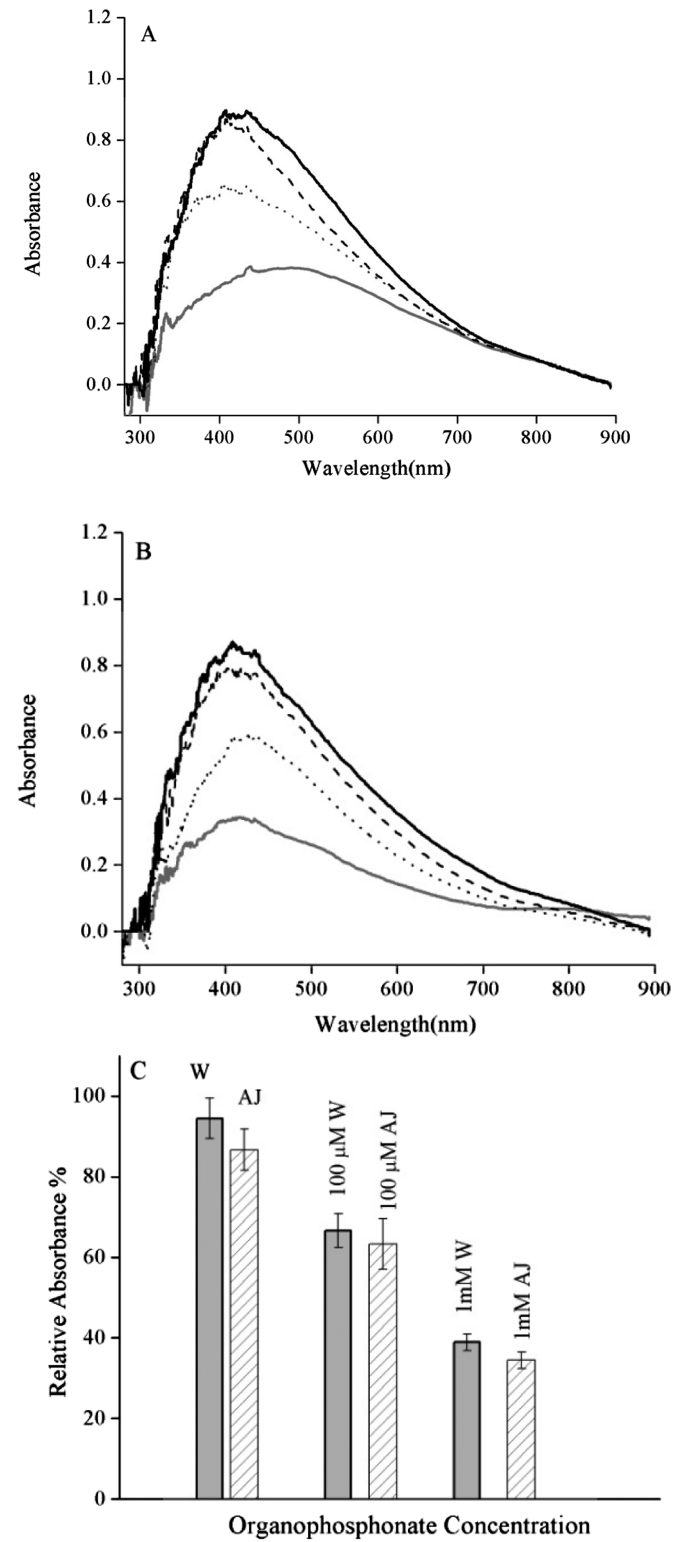

Fig. 3 LSPR response of OP modified Ag NSs. (A) Absorbance intensity against wavelength to show decrease in Fresnel signal as different $O P$ concentration bind to Ag NSs surface in tap-water (A) and apple juice (B) for bare Ag NSs (solid black line), modified Ag NSs with pure tapwater (A) or apple juice (B) (dash line), modified Ag NSs with $100 \mu \mathrm{M}$ OPs in tap-water (A) and apple juice (dot line) and modified Ag NSs with $1 \mathrm{mM}$ OPs in tap-water (A) and apple juice (solid gray line). (C) Shows the relation between relative absorbance reduction with enhancement of OPs concentration in tap-water and apple juice. The change in reflectance intensity was monitored at $400 \mathrm{~nm}$.

knowledge, there has not been any report to apply LSPR for the detection of these organophosphates.

Lastly, it is worth nothing that the approval levels of malathion, fenthion and ethion by the US Food and Drug Administration is $0.2 \mathrm{mM}, 0.36 \mu \mathrm{M}$ and $1.04 \mathrm{nM}$ respectively. ${ }^{2}$ Thus, our results are promising for the rapid monitoring of presence of OPs in tap-water or apple juice by electrochemical and LSPR techniques. 


\section{Conclusions}

In summary interaction of OPs with Ag NSs leads to impedance enhancements, resulting in reductions of the current intensities as monitored by SWV and LSPR absorbance decrease. These results suggest the ability to monitoring the interaction of $\mathrm{P}=\mathrm{S}$ containing organophosphonates using nanostructured silver surfaces. However, at this point, there is no selectivity and in order to achieve higher detection limits, modification of $\mathrm{Ag}$ NSs surfaces with a linker that selectively captures just one of the OPs is proposed. We are currently pursuing this avenue, since it may enable us to develop a useful platform for dual electrochemical and LSPR sensing of OPs in complex matrices.

\section{Acknowledgements}

We would like to thank NSERC and the University of Toronto Scarborough for financial support of this research.

\section{References}

1 http//: www.epa.gov/pesticides/food/pest.html.

2 B. B. Narakathu, W. Gua, S. O. Obare and M. Z. Atashbar, Sens. Actuators, B, 2011, 158, 69-74.

3 W. Guo, B. J. Engelman, T. L. Haywood, N. B. Blok, D. S. Beaudois and S. O. Obare, Talanta, 2011, 87, 276-283.

4 G. Liu and Y. Lin, Anal. Chem., 2007, 77, 5894-5901.

5 B. Jin, L. Xie, Y. Guo and G. Pang, Food Res. Int., 2012, 46, 399-409.

6 J. Fenik, M. Jankiewicz and M. Biziuk, TrAC, Trends Anal. Chem., 2011, 30, 814-826.

7 M. R. Gravett, F. B. Hopkins, M. J. Main, A. J. Self, C. M. Timperley, A. J. Webb and M. J. Baker, Anal. Methods, 2013, 5, 50-53.

8 X. Sun and X. Wang, Biosens. Bioelectron., 2010, 25, 26112614.

9 W. Zhao, P. Y. Ge, J. J. Xu and H. Y. Chen, Environ. Sci. Technol., 2009, 43, 6724-6729.

10 S. Samadi, H. Sereshti and Y. Assadi, J. Chromatogr., A, 2012, 1219, 61-65.

11 D. Lu, Y. Yang, X. Luo and C. Sun, Anal. Methods, 2013, 5, 1721-1732.

12 C. De, T. A. Samuels, T. L. Haywood, G. A. Anderson, K. Campbell, K. Fletcher, D. H. Murray and S. O. Obare, Tetrahedron Lett., 2010, 51, 1754-1757.
13 D. D. Erbahar, I. Gurol, G. Gumus, E. Musluogla, Z. Z. Ozturk, V. Ahsen and M. Harbeck, Sens. Actuators, B, 2012, 173, 562-568.

14 M. Trojanwicz, Electroanalysis, 2002, 14, 13111328.

15 M. Zourob, K. G. Ong, K. F. Zeng, F. Monffonk and C. A. Grimes, Analyst, 2007, 132, 338-343.

16 J. Yguerabide and E. E. Yguerabide, Anal. Biochem., 1998, 262, 137-156.

17 S. K. Srivastava, V. Arora, S. Sapra and B. D. Gupta, Plasmonics, 2012, 7, 261-268.

18 A. J. Haes and R. P. VanDuyne, J. Am. Chem. Soc., 2002, 124, 10596-10604.

19 K. S. Lee and M. A. El-Sayed, J. Phys. Chem. B, 2006, 110, 19220-19225.

20 A. Kumaravel and M. Chandrasekaran, Sens. Actuators, B, 2011, 158, 319-326.

21 A. Kumaravel and M. Chandrasekaran, Sens. Actuators, B, 2012, 174, 380-388.

22 L. Kashefi-Kheyrabadi and M. A. Mehrgardi, Biosens. Bioelectron., 2012, 37, 94-98.

$23 \mathrm{~W}$. Song, H. Li, H. Liu, Z. Wu and D. Xu, Electrochem. Commun., 2013, 31, 16-19.

24 F. Fathi, M. Schlitt, D. B. Pedersen and H. B. Kraatz, Langmuir, 2011, 27, 12098-12105.

25 F. Fathi, F. Lagugné-Labarthet, D. B. Pedersen and H. B. Kraatz, Analyst, 2012, 137, 4448-4453.

26 F. W. Campbell and R. G. Compton, Int. J. Electrochem. Sci., 2010, 5, 407-413.

27 Y. Tang and T. E. Furtak, Electrochim. Acta, 1991, 36, 18731877.

28 E. Herrero, L. J. Buller and H. D. Abruna, Chem. Rev., 2001, 101, 1897-1930.

29 R. P. Janek, W. R. Fawcett and A. Ulman, J. Phys. Chem. B, 1997, 101, 8550-8558.

30 E. Boubour and R. B. Lennox, Langmuir, 2000, 16, 7464-7470.

31 J. C. Love, L. A. Estroff, J. K. Kriebel, R. G. Nuzzo and G. M. Whitesides, Chem. Rev., 2005, 105, 11031169.

32 E. Katz and I. Willner, Electroanalysis, 2003, 15, 913-947.

33 R. A. Bell and J. R. Kramer, Environ. Toxicol. Chem., 1999, 18, 9-22.

34 E. Barsoukov and R. MacDonald, Impedance Spectroscopy: Theory, Experiment, and Applications, John Wiley \& Sons, Inc., Hoboken, NJ, 2005, 2nd edn, ch. 2, pp. 37-39. 